\title{
Workflow management: enabling process integration in production management
}

\author{
M. Rosemann" , Chr. von Uthmann" , D. Frink \\ ${ }^{1)}$ Queensland University of Technology \\ School of Information Systems \\ 2 George Street, GPO Box 2434, Brisbane Q 4001, Australia \\ Tel: +61 738641125 , Fax: +61738641969 \\ e-mail:m.rosemann@qut.edu.au \\ ${ }^{2}$ University of Muenster, Department of Information Systems \\ Steinfurter Str. 107, 48149 Münster, Germany \\ Tel: +49 (0)251/83 38 064, Fax: +49 (0)251/83 38109 \\ e-mal: ischut@wi.uni-muenster.de \\ ${ }^{3}$ Research Institute for Operations Management at University of \\ Technology, Pontdriesch 14/16, 52062 Aachen, Germany \\ Tel: +49 (0)241/47705-42, Fax: +49 (0)241/402401 \\ e-mail: fk@fir.rwth-aachen.de
}

\begin{abstract}
So far workflow management as an organizational and technical approach to integrate business processes has mainly been discussed in the area of office management and in service industries like banks or insurance companies. This paper describes the general characteristic of processes that are appropriate for workflow-support. Processes with these characteristics can be identified within the main areas of production management, namely construction, production planning and control and quality management. Finally, this paper ends up suggesting two different approaches for possible workflow-based PPC-architectures.
\end{abstract}

Keywords

Process management, workflow model, construction, production planning and control, quality management 


\section{OBJECTIVE}

While the term computer integrated manufacturing (CIM) has been loosing popularity rapidly, data, function and process integration as the main objectives of this philosophy are still of high relevance to a realization of efficient production management systems. In the past, it has been dealt intensively with data integration and integrated database management systems can be found in nearly every company. In contrast to this, the industrial sector is scarcely paying attention to process integration. Since the beginning of this decade the focus on integration efforts is shifting towards process management. In this context, process orientation is discussed under organizational concepts like Lean Production, Just in Time, Total Quality Management, Supply Chain Management, EN ISO900x or Business Process Reengineering. Integrated information systems do not only have to provide applications and data for supporting single activities of business processes but also need to support the process control for the coordination of logical dependent activities.

Similar to database management systems that support the integration of data, workflow management systems (Jablonski, Bussler 1996; Kobielus, 1997) have been developed to support the integration of functions within business processes. Although these workflow management systems have meanwhile reached a high degree of functionality and stability and are intensively used in service industries like banks or insurance companies they have been considered in production management only to a minor extent.

This paper contributes to a placement of the term and the concept of workflow management into the context of production management systems. By taking the integration dimensions of the computer integrated manufacturing approach, the characteristics and the intention of workflow management systems are marked off. Thereafter, it will be analyzed which processes in production management are appropriate for workflow support and which are the main benefits of using workflow management as support for these processes. The potential of workflow management will be ascertained for the key processes in manufacturing systems: construction, production planning and control, and quality management. Finally, two possible approaches for a workflow-based architecture for PPC-systems will be differentiated.

\section{CHARACTERISTICS OF WORKFLOW MANAGEMENT}

Workflow management is a discipline of office management and computer supported cooperative work (CSCW) (Dix, 1994). It can be defined as the modeling, execution and control of business processes. Workflows are processes with automated transitions between the embedded activities. The transitions from activities to their succeeding activities are controlled by an information system, the workflow management system. Workflow models are usually described as directed graphs whose nodes represent elementary or composite functions (Jablonski, 
Bussler, 1996; Weske, Vossen, 1998). In addition to a model for a business process, a workflow model has to consist of (Rosemann, 1998; Rosemann, zur Mühlen, 1998)

- input and output data for every function;

- precise descriptions at the splitting and joining nodes;

- organizational responsibilities for every function, usually depicted as roles;

- specification of the invoked applications (location, parameters).

Workflow management systems are characteristically designed as middleware. They separate the process control from application systems. Consequently - from the viewpoint of a workflow management system - the functions within a process are black-boxes. One central function of workflow management, which is the automated coupling of single activities targets the decrease of transfer errors, transport time and idle time, as well as the reduction of routine work for employees, the support of parallel processing and a just-in-time information transfer. The second central function is the assignment of work items to workflow participants via a worklist. These assignments are proceeded during the runtime of a workflow according to qualification and organizational properties specified as roles. The notification, synchronization and handling of worklists support the efficient cooperation of workflow participants with regard to the completion of the work items within workflows. A further important aspect of workflow management is workflow monitoring which enables partially automated supervision of workflows within control circuits. For this purpose, the workflow log files (audit trail) can be converted, aggregated and used within a process information system that includes different statistical methods (clustering) or early warning functions in order to support the process owner.

Processes which can be supported by workflow management systems have the following characteristics:

- The processes are at least partially pre-structured, i. e. processes can be described in advance through process models. Processes which can only be determined during runtime - so-called ad-hoc-processes - will rather be supported by groupware systems.

- Due to restrictions of the economic efficiency of modeling and execution activities, the processes to be supported with workflow management systems should be executed with a certain frequency within a period.

- The processes are performed by several workflow participants resp. several application systems working together asynchronously.

Only in these cases it is worthwhile to profit from the coordinative functionality of workflow management systems. In addition to these main prerequisites, further technical, organizational and economical criteria have to be taken into account in order to identify the most appropriate processes for workflow support (Becker et al., 1999).

Processes with these characteristics can principally be found in manufacturing systems (Rosemann, von Uthmann, 1997; Rosemann, von Uthmann, 1999). In contrast to purely administrative processes, a special property of production processes is their correspondence to material flows whose control implies special 
requirements for information systems. Moreover, processes in manufacturing systems tend to be complex through the involvement of many departments (see the construction process as an example). Furthermore, the heterogeneous system environment consisting of administrative applications like PPC-software and more technical components like computer aided engineering/design/manufacturing requires to manage various interfaces and the handling of different coexisting data formats. Hence, in comparison to the purely administrative sector, processes in manufacturing systems are characterized by complex organizational and technological conditions which impede the utilization of workflow management. Having this in mind; in the following chapter the potential of workflow management systems is analyzed for the essential industrial processes in the areas of construction, production planning and control, and quality management.

\section{POSSIBLE WORKFLOWS IN PRODUCTION MANAGEMENT}

In construction, there is a high demand for structuring and representing processes in a more transparent way, as well as for a goal-directed use, re-use and modification of existing information. Though organizational principles and action guidelines have been set up, the essential precondition for typical workflow management systems is hardly being considered. An appropriate workflow management solution for the support of construction processes has to be flexibly adaptable to the individual product requirements and unforeseen situations within running processes. A proposal for a solution of this problem is the concept of workflow-based business process control (von Uthmann, 1998). It is based on the creation of model components referring to work items which can be assembled according to individual products and specific situations. Workflows in this area have to handle complex product data as well as administrative data like material master data or bill-of-materials. Besides the general advantages of workflow management, the main benefit of using this middleware for the execution of engineering processes is the standardization of these processes that are usually not planned. Data gained by workflow monitoring can be used to better calculate the engineering time and leads to a more realistic estimation for the entire order processing time and the prize calculation. In most cases, the critical time-to-market can be reduced significantly.

As far as the use of workflow management for production planning and control $(P P C)$-processes is concerned it can be stated that the control systems implemented within the last thirty years do already perform large parts of the functions. Nevertheless, the existing solutions mainly support PPC-functions individually and do not take a holistic process perspective into account. Furthermore, they are often limited to a process logic that is conform with the MRP II (Manufacturing Resource Planning) framework and that supports only the pure PPC-processes without sufficiently integrating administrative functions like accounting or human resource management. As a consequence, several potentials 
for the use of workflow management can be identified, which can increase the degree of process orientation within PPC-systems.

One principle of quality management is to secure a managed level of quality by controlling processes within integrated process control circuits. In this context, the potential of workflow management is presented in the basic model of workflowbased business process modeling which describes the structure of a cascading control in three circuits with workflow management as key component of true value generation and regulation (von Uthmann, 1998). The automation of function transitions contributes to the improvement of process control by minimizing errors caused by manual influences. At the same time the implementation of workflowbased control circuit systems together with an increasing employees' involvement can help to identify and compensate quality defects during the processing of workflows. Parallel to the execution, audit trails can be automatically created as a comprehensive process audit. These data can be aggregated and presented by process information systems (PIS). Such a system would enable to identify critical trends concerning the process performance immediately and to trigger appropriate compensation mechanism. Moreover, the process models created during workflow specification can be used for the documentation of processes necessary for a certification following standards like the EN ISO 900x.

\section{TWO ARCHITECTURES FOR A WORKFLOW-BASED PPC}

Focussing on production planning and control, this chapter explains two possible architectures for a workflow-based PPC. The two architectures can be differentiated by their requirements concerning the necessary modification of the PPC-system.

The first architecture is characterized by the fact, that it requires only relative minor changes of the existing PPC-system. It increases the degree of process orientation as it integrates the single PPC-functions along processes. Characteristically, in this workflow-integrating architecture the workflow management system is an additional system on top of the PPC-system. On the same level of abstraction, this approach aims to integrate related applications in the area of financial accounting, cost and revenue controlling, asset management, or human resource management. Consequently, such an approach is interesting for companies that are planning to exchange their PPC-system in a few years and are not willing to invest heavily in their current PPC-system. Nevertheless, this architecture streamlines the use of the PPC-system and reduces problems at the interfaces between the PPC-system and other related applications. In this case, the workflow-based processes still follow the concept of MRP II.

An example for a workflow fitting to this scenario is the process of invoice verification, which integrates functionality belonging to material management in the first part of the process with the accounts payable module of financial accounting in the second half of the process. Figure 1 shows the general principle of this architecture. Existing functions in a PPC-system are re-grouped in a process 
that is executed by a workflow management system. The granularity of the embedded functions is the same as in the PPC-system without a workflow management system.

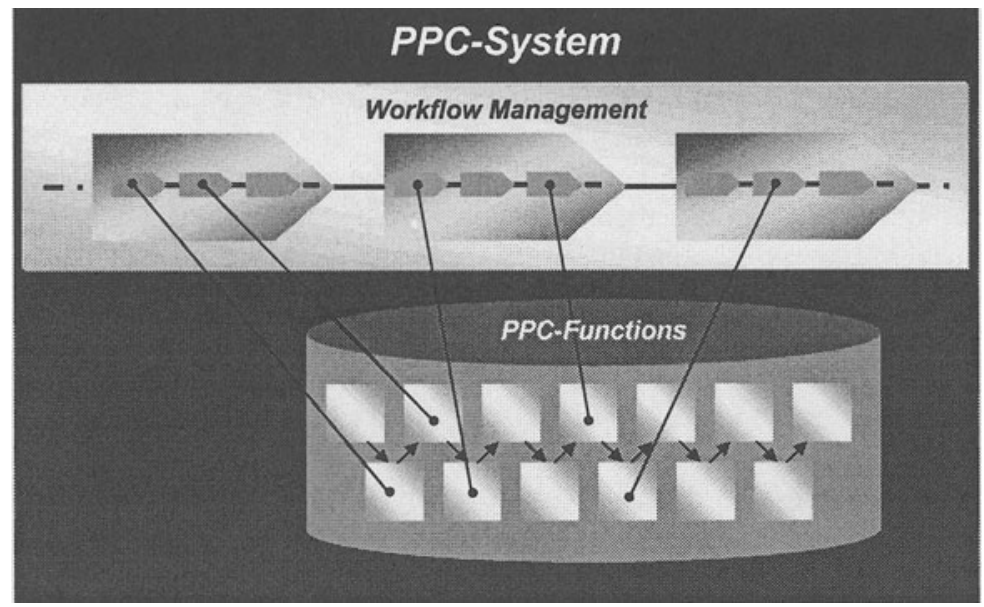

Processes

Functions

Figure 1 Workflow-integrating PPC-architecture

In addition to the objectives of the first architecture, the second suggestion is far more innovative as it changes the granularity of the embedded PPC-functions to make alternative logical sequences of activities possible. The main motivation is to enable processes that are different to typical MRP II processes. An example for this are the requirements of the furniture industry: In this branch, the results of transportation planning are input data for the capacity management. Finally, material management has to calculate the demand for material and products. Besides industry-specific requirements, the demand for alternative PPC-processes can also result from PPC-philosophies like the Optimized Production Technology (OPT) (Goldratt, 1988) approach, that starts with the identification of typical bottlenecks followed by capacity management for the other machines, lot size optimization and material management. In order to realize these kind of processes, it is indispensable to restructure the functions of a PPC-system. In comparison with architecture 1, the functions must be of a finer granularity. An efficient execution of these processes still depends on the support from workflow management systems, which is in this case an embedded module of the PPC-system (workflowbased architecture).

As a consequence, such an architecture is of relevance to manufacturing companies with individual requirements concerning the desired sequence of activities. Furthermore, they should use a PPC-system that is easy to divide in submodules. Ideally, the architecture of the PPC-system follows the principles of object orientation. Figure 2 stresses the main idea underlying this architecture. 


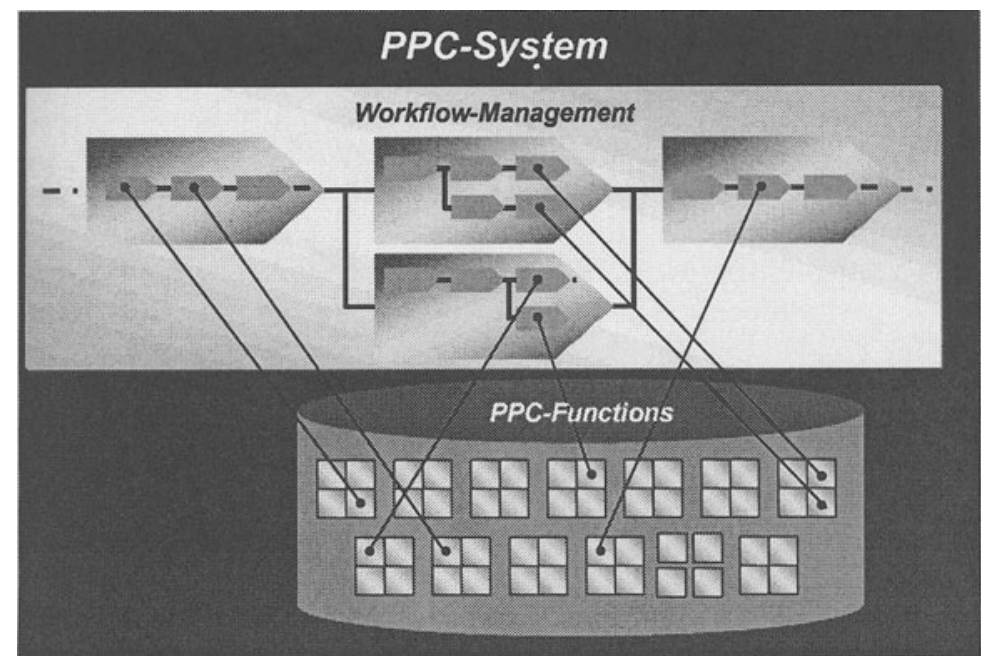

Flexible

Processes including Variants

Figure 2 Workflow-based PPC-architecture

Currently, the University of Münster, Department of Information Systems, the Research Institute for Operations Management (FIR) at Aachen University of Technology, four manufacturing companies, a workflow provider and a software company providing a PPC-solution are working together in the research project "PROWORK - prodcution planning and control with workflow management systems for a more efficient order processing" on a reference model for a workflow-based PPC-architecture. The aim is to put the two architectures described above in concrete terms and to develop a generic procedure model for the introduction of workflow management into the area of production planning and control. Actually, we are consolidating existing reference models and identifying processes that could be realized as workflows. It is planned to implement selected workflows in the PPC-domain at the participating manufacturing companies in order to get an empirical evidence for the research results (see also von Uthmann, Stolp, Meyer, 1997).

\section{REFERENCES}

Becker, J., von Uthmann, Chr., zur Mühlen, M. and Rosemann, M. (1999) Identifying the Workflow Potential of Business Processes, in Proceedings of the Hawaii International Conference on System Sciences (HICCS).

Dix, A. (1994) Computer Supported Cooperative Work: A Framework, in Design Issues in CSCW (eds. D. Rosenberg, Chr. Hutchison), London et al., 9-26.

Goldratt, E. M. (1988) Computerized shop floor scheduling, in International Journal of Production Research, 3, 443-455.

Kobielus, J.G. (1997) Workflow Strategies, Foster City, CA, et al. 
Jablonski, St. and Bussler, Chr. (1996) Workflow Management. Modeling Concepts, Architecture and Implementation. London et al.

Rosemann, M. (1998) Managing the Complexity of Multiperspective Information Models Using the Guidelines of Modeling, in Proceedings of the $3^{\text {rd }}$ Australian Conference on Requirements Engineering (eds. D. Fowler, L. Dawson), Geelong, 101-118.

Rosemann, M. and zur Mühlen, M. (1998) Evaluation of Workflow Management Systems - A Meta Model Approach. Australian Journal of Information Systems, 1, 103-116.

Rosemann, M. and von Uthmann, Chr. (1997) Workflow Management in Manufacturing (Workflowmanagement in der industriellen Produktion). ZWFZeitschrift für wirtschaftlichen Fabrikbetrieb, 7-8, 351-354.

Rosemann, M. and von Uthmann, Chr. (1999) Workflow Management as a Foundation for a Process-oriented PPC (Workflowmanagement als Basis einer prozeßorientierten PPS). PPS Management, 1, 27-31.

von Uthmann, Chr. (1998) Workflow-based Business Process Control: An Approach to Improve the Management of Concurrent Engineering, in Proceedings of the $5^{\text {th }}$ ISPE International Conference on Concurrent Engineering - CE '98 (eds. S. Fukuda, P.K. Chawdhry), Tokyo, Japan, 223227.

von Uthmann, Chr., Stolp, P. and Meyer, G. (1997) Workflow Management in Integrated Applications: A Report about the Workflow-Project at the ABB Turbinen Nürnberg $\mathrm{GmbH}$. (Workflowmanagement in integrierten Anwendungssystemen: Ein Bericht über das Workflow-Projekt der ABB Turbinen Nürnberg $\mathrm{GmbH}$ ), in HMD-Theorie und Praxis der Wirtschaftsinformatik, 198, 107-114.

Weske, M. and Vossen, G.: Workflow Languages (1998), in Handbook on Architectures of Information Systems (eds. P. Bernus, K. Mertins, G. Schmidt), Berlin et al., 359-379.

\section{BIOGRAPHY}

Michael Rosemann, Dr. rer. pol., Dipl-Kfm., born 1967, studied Business Administration at the University of Münster. He worked for the Department of Information Systems, Münster, from 1992-1999. He received his Ph. D. in Information Systems in 1995. His dissertation dealt with complexity management in process models. Since 1. August 1999 he is Senior Lecturer at the Queensland University of Technology, Brisbane, Australia. His main areas of research are production planning and control, logistics, enterprise resource management, information modeling, and workflow management. Together with Prof. Dr. Jörg Becker he is leading the project "Controlling and monitoring of distributed workflows for a continuous optimization of business processes". This project is funded by the German Research Society. 
Christoph von Uthmann, Dipl-Wirt. Ing., born 1967, studied Business Engineering at the University of Padcrborn. He is working for the Department of Information Systems, Münster, since 1996. His main areas of research are production planning and control, concurrent engineering, simulation, information modeling, and workflow management. He consulted a manufacturer with the implementation of a workflow management system. Christoph von Uthmann is a member of the research project PROWORK - production planning and control with workflow management systems for a more efficient order processing", which targets to develop architectures fo a workflow-based PPC.

David Frink, Dipl.-Kfm., born 1972, studied Business Administration at Aachen University of Technology after finishing a two-year-practical training at a major German bank. He is working for the Research Institute for Operations Management, Department of Production Management, Aachen, since 1996. His focus of research are the areas of production planning and control, technical order processing, information modeling, and engineering data management. $\mathrm{He}$ consulted various enterprises with the selection and implementation of PPC and ERP systems. David Frink is a member of the research project "PROWORK production planning and control with workflow management systems for a more efficient order processing", which targets to develop architectures for a workflowbased PPC. 